\title{
The Moderating Effect of the Economic Situation on Relationship between Problem-Solving Skills and Mental Health in Working Women and Housewives
}

\author{
Maryam Safara ${ }^{1} \&$ Goldis Garmsari ${ }^{2}$ \\ ${ }^{1}$ Psychology Department, Women Research Center, Alzahra University, Tehran, Iran \\ ${ }^{2}$ Islamic Azad University, Saveh Branch, Saveh, Iran \\ Correspondence: Maryam Safara, Psychology Department, Women Research Center, Alzahra University, Tehran, \\ Iran. Tel: 98-218-569-2080. E-mail: m.safara@alzahra.ac.ir
}

Received: April 26, 2017

Accepted: May 9, 2017

Online Published: June 8, 2017

doi:10.5539/hes.v7n3p1

URL: http://doi.org/10.5539/hes.v7n3p1

\begin{abstract}
Women as an important stratum of society play a fundamental role in the creation, establishment and strengthening of families. So, paying attention to their mental health as the family guides has direct effects on the mental health of children, families and consequently the whole of society. Thus, the present study was performed to investigate the moderating effect of the economic situation on the relationship between problem solving skills and mental health in two groups of working women and housewives referring to Welfare Centers in the city of Karaj. Based on Morgan's sampling table, 199 working women and 192 housewives (totally 391) were selected by simple random sampling method. Then, Cassidy and Long (1996) Problem-Solving Style Questionnaire and Goldberg (1989) General Health Questionnaire were administered on the sample group, and data were analyzed using SPSS software (ver. 17). The results showed that the economy had an independent contribution in predicting the mental health of working women, but it was not capable to act as a moderating variable in relationship between problem-solving skill and mental health of working women. In addition, according to the results obtained from the housewife population, not only the economy does not have an independent contribution in the prediction of their mental health, but also it cannot act as a moderating variable in this relationship. But the problem-solving skill alone explains $23.8 \%$ of the variance of mental health in the sample population. In other words, problem-solving ability was effective in increasing the level of mental health. But the impact of economy as a moderating variable in the relationship between problem-solving skill and mental health of housewives and working women was not significant.
\end{abstract}

Keywords: mental health, problem-solving skill, economic status, working women, housewives

\section{Introduction and Statement of Problem}

According to a definition by the World Health Organization (WHO), mental health only does not mean the absence of mental illness, but rather it relates to a type of the mind health. Those people are mentally healthy who feel that they can compromise life, its changes and related issues and can control their life, to be responsible to do their duties, to make good use of their mental abilities, to establish a good relation with other people and to do constructive activities (Khoda Rahimi, 2004). With the progress of science and the development of personal and social relationships, more attention has been paid to psychological and emotional issues of people. The importance of individuals' mental health, attention to the criteria and the ways to preserve and maintain them among different communities has been increased and the abundant scientific researches in the field of prevention and treatment of psychological disorders are the witnesses of this issue (Mohammadzadeh, 2012). It seems that expectation from women is higher due to their existential nature in terms of physics and emotion that this issue leads to increase mental-social pressures on women and influence on all (physical, mental and social) dimensions of health in this group. All these maters indicate the importance of health, especially mental health in women (Hajjilu \& Ramzi, 2014). On the other hand, facing with problem in everyday life is a natural and inevitable fact and individuals are faced with various problems throughout their lives, so the individuals' ability to deal with such situations in the right way and efficiently is of great importance (Pugliese \& White, 2013). In fact, according to Hogan (1995) mental health can usually be defined in three ways: as self-conscious or lack of self-deception, accepting to follow 
the destiny of humanity, and solving internal conflicts and contradictions. So, one of the variables that are closely associated with mental health is the same issue of solving conflicts and the variable of problem-solving skill. Psychological well-being is one of the factors affecting the problem solving. Problem solving is a critical skill for living in the current era. Today, in all activities the specialists are called for higher order thinking skills and problem solving, whether in the public sphere and in the area of technology, or in normal activities and or in the problematic activities; and in most societies, all people believe that we must emphasize on increasing the problem solving skill (Chaster \& Drynforth, 1996; quoted in Agha Yousefi, 2011). Problem solving skill is a cognitive-behavioral process, by which people discover and identify the effective coping strategies to deal with problematic situations in life. In general, problem solving skill refers to a cognitive-behavioral-innovative process by which a person is going to discover or invent adaptive and effective coping strategies for everyday problems. In other words, problem solving is an important coping strategy that increases the ability and personal and social development and decreases the stress and mental health problems. Problem solving is a general strategy by which individuals find effective coping responses for challenging situations (Dezverila \& Shadi, 1992; quoted in Barghandan, 2009). According to Black and Harsen (1995), problem solving is very important for psychological adjustment because in the scope of stressful situations, it affects on the adaptive function. Compromise and successful adaptation to the social environment require a set of interpersonal problem-solving skills (Barghandan, 2009). One of the things that are directly related to the mental health, especially in women, is employment. However, in literature we gradually witness the emergence of a synthesis of the two (positive and negative) approaches to women's health-employment relationship. Riess (2005) has shown that job creation can facilitate the context of individuals' growth in the economic, social and cultural aspects. Apart from the financial aspects and income resulted from employment, the effective factors such as changes in the cultural, social and psychological fields are the positive consequences of job creation, especially in women's population. Factors such as creating self-esteem, a feeling of being useful to society, physical health, and promotion of social status, mental health and removing social exclusion are the consequences of job creation (Toozandehjani, 2009). Employment is one of the variables that affect mental health and problem solving ability, especially in the population of women. Since employment constitutes an important part of a working person's life, it is expected that the employment situation and the individual's attitude to her/his job have a meaningful role in the quality of her/his life. Employment status of the person, which includes factors such as work experience, number of working hours, employment rank, and the proportion of jobs with expertise and employment situation can be a source of special effects. For example, findings of a research by Ahmadnia (2004) on 710 employed women showed that those who are satisfied by diversity of job, being interesting and control on the job trend enjoy higher levels of mental health (Jawaheri et al., 2010). Therefore, favorable conditions of work and employment status will have a direct impact on increasing the level of women's mental health. Woman's mental health has an interactive impact in her relationship with her family, including her husband and children. Thus, we must think of concrete measures in the field of women's employment status, their working hours, earnings, etc., because this investment has a direct impact on family strengthening and successful delivery of a generation of children in the future. But unfortunately, no concrete measures have been done in the field of women's employment status and even condition of employment between women and men are the same in many organizations. According to the importance of mental health, especially in the women's population, and the effects of variables such as employment on women's mental health, it is required that we pay more attention to the effects of occupation on women's mental health, and also the role of moderating variables in their status of mental health, including economic status, should be examined. So in this study, we try to evaluate the relationship between problem solving skills and mental health in working women and housewives, considering the moderating effect of the economic situation and seek to answer following questions.

Does the economic situation moderate the relationship between problem solving and mental health?

Does the economic situation moderate the relationship between problem solving and mental health of working women?

Does the economic situation moderate the relationship between problem solving and mental health of housewives?

\section{Conceptual Atmosphere}

In this study according to the nature of the subject, mainly two concepts of mental health and problem solving skill have played the role of directing and organizing the results that we briefly explain about these concepts in the following sections.

In the Larousse dictionary, mental health has been defined as follows: mental aptitude for coordinating, making pleasant and efficiently working, being flexible in difficult situations and having ability to recover his balance 
(Ganji, 2003). Psychological well-being includes the understanding of an individual from the coordination between the certain and outlined objectives with functional consequences obtained in the ongoing process of evaluating and results in relatively stable and inner satisfaction in the life sequence. Well-being refers to the sense of health which includes full awareness of integrity and unity in all aspects of a person. Psychological well-being is a part of the life quality psychology which has been defined as people's perception of their own lives in terms of emotional behavior, mental performances and dimensions of emotional health (Agha-Yousefi \& Sharif, 2001). In fact, psychological well-being is the individuals' assessment of his/her current and previous years of life and includes the emotional and cognitive aspects (Angela, 2008) that includes the individuals' emotional reactions to psychological states and their judgments on the level of the life satisfaction, perfection, sufficiency and satisfaction with specific are as such as marriage and work, and generally well-being deals with what people call it happiness and satisfaction (Steinberger, 2007). But problem solving skill is one of the great actions of minds and, one of the components of self-management skill (Gerkensmeyer et al., 2013) in which a person by establishing a relationship between past experiences and the problem must discover relationship between the mand accordingly select the appropriate solution (Esra, 2013). Problem solving skills directly relate to adjustment issue. On the other hand, deficits in problem solving skills lead to a variety of disorders, including depression, anxiety, confusion, and problems related to marriage and child rearing, improper interpersonal relationships and overall mental health problems for the people. Mental health of people is influenced by the environment they live in. Lack of access to material resources and the stresses caused by low socioeconomic status affect mental health and consequently people's problem solving skills. Enjoyment of desirable social and economic situation (higher income, number of rooms, having computer and teaching aids, etc.) makes the relationship between parents and children better and the proper situation resulted from this desirable relationship leads to increased mental health and contribute to the strengthening of solving issues in people (Barriuso-Lapersa et al., 2012).

\section{Theoretical Framework}

In relation to mental health, there are several theories; for example, according to Fromm (1968) a man with mental health is one who deeply loves, is creative, and has completely developed the individual power and reasoning in himself and profoundly understands the self and the world. He has right stable feeling, connects with the world and has its root and origin in it and dominates his fate. Fromm knows the healthy human as one with a fertile orientation; that is, a type of orientation in which the person is able to apply all his power and potential aptitude (Mousavi, 2010). But according to Skinner's theory (1973) mental health in a healthy person is in accordance with the behavior of the laws and regulations of the society and such a person, when faced with difficulty, wants help from people around him through the method of the behavior correction for improving and normalizing his behavior and the behavior of people around him. He continues this work until the behavior reaches to normal level adopted by the society. Healthy human is one who receives more social impact form the environment and people due to his proper behavior (Rezaei, 1999, pp. 60-62). Also according to Ericson's theory, each individual's psychological health is the same that he had been able to acquire the ability proper to each stage of life. Ericsson has offered the distinctive traits of psychological health as follows: a person who lives in the community must be free of conflict, as well as, use the clear ability and talent, and must be master and skillful in his work and have unlimited initiative. He must get feedback of his career in any stage and ultimately have a clear and understandable opinion about his life process (Sadeghipour, 2012). But according to Salivan, mental health features include: 1) The personality that enjoys flexible mental health and is flexible in his relations with others according to new interpersonal situations, 2) Healthy person is able to distinguish between the increase and decrease of stress and his behavior is directed at reducing stress, 3) According to Salivan, the healthy personality should be training and acquiring relations and communications such that Richard states, 4) The life of a person who enjoys mental health has orientation. This means that he integrates his desires in a way that leads to satisfaction, or reduces or removes his anxiety relatively. Therefore, a healthy personality is one whose mental system has a little stress, and such a person usually has flexible and trusting social relations (Mousavi, 2010). According to what was mentioned and the need for attention to mental health, the hypotheses of the study are presented as follows:

\subsection{Hypotheses}

1) Economic status has a moderating effect on relationship between problem-solving skill and mental health.

2) Economic status has a moderating effect on relationship between problem-solving skill and mental health in working women.

3) Economic status has a moderating effect on relationship between problem-solving skill and mental health in housewives. 


\section{Literature Review}

In reviewing the empirical literature, in order to clarify the scope of the topic, the summaries of several researches are reported: Nick Azin et al. (2013) in a study entitled "the quality of life related to health in adolescents: differences in mental health, socio-economic status, gender and age" with a sample group of 551 high school and guidance students in the city of Yazd (including 275 females and 276 males) concluded that: 1) In the physical well-being scale, psychological well-being, relationships with parents, and social support, the male students had better condition than female students; 2) Secondary (guidance) school students in all aspects of KIDSCREEN-52 questionnaire had better condition than high school students except for peer and social support, social acceptance and harassment, and financial resources; 3) Physical and mental health among students with high socio-economic status was significantly different from that of students with low socio-economic status. Also AhmadiDeh Qutbal-Dini (2010) conducted a study entitled "the relationship between family socio-economic status, learning strategies and mathematical problem solving ability among university students" on 427 students of Khorasgan Islamic Azad University (in Isfahan province) through cluster sampling method. The result showed that the relationship between mastery goals and learning deep strategy and mathematical problem solving ability was positive and significant, but the relationship between performance-orientation goals and avoidance goals with mathematic problem solving ability was not significant. The relationship between deep strategies and mathematical problem solving ability was positive and significant and the relationship between surface strategies and mathematic problem solving ability was not significant. The results also showed that there was not any significant relationship between learning strategies and problem-solving ability in terms of gender and socio-economic status. Rezapour et al. (2010) carried out a study under the title of "the relationship between students' religiosity and socio-economic status and life satisfaction with moderating effect of the mental health components" on 495 university students ( 246 females and 249 males). The findings showed that the direct effect of religiosity on mental health component and life satisfaction was significant. Also, the direct effect of anxiety, social function and depression on life satisfaction was significant and the effect of socio-economic status on endogenous variables of research (components of mental health and life satisfaction) was not significant except for anxiety. Walker et al. (2013) in a study entitled "the effect of training problem solving skills on behavioral problems" concluded that children's behavioral problems such as stubbornness, conduct problems and antisocial behaviors, seclusion, isolation and embarrassment are improved by learning problem solving skills and cognitive changes, and anger management skills and good communication with peers, social acceptance and positive feedback towards the self are increased in them. Özdemir et al. (2013) performed a study under the title "assessment of the relationship between problem solving and mental health on the Youthin Turkey". According to the results of this research, problem solving and depression are the important factors in understanding the anger among the people. The results showed that problem solving skill had a significant negative relationship with anger and depression (as mental health variables). Barriuso-Lapresa et al. (2012) performed a study entitled "the impact of education on mental health in 4-15 year-old Spanish children". According to the findings of the research, the children whose mothers had primary education and lower economic status had lower mental health status than those who had higher education in the family and higher economic status. Phelan (2010) in a research under the title of "the impact of education on lifestyle, health awareness and mental health-related quality of life" came to the conclusion that the improvement of the respondents' scores in all three components was because of increasing the level of education. This was especially evident in the higher education so that people with higher education had significant differences with the rest in all three variables.

Therefore, according to the results of the researches done in this field the relationship between problem-solving and mental health (or its components) seems significant, but the moderating role of economy in some studies was significant and in some was insignificant. Thus, the present study was performed to make clear this problem and do initiatives and provide new suggestions.

\section{Methodology}

The present study was theoretical in terms of objective, so that the data collection was performed using measuring instruments of standard questionnaires. This study is also an inferential-descriptive one and of correlational type in terms of collecting data from libraries, theses, articles, etc., and in terms of executive method, in which researcher merely predicts the concurrent relationship of variables without manipulating them. The study population consisted of all employed and unemployed women (clients) referred to Welfare Organization of the city of Karaj in 2015 that the total number of them was 720 (400 working women and 380 housewife). Based on Morgan table, the sample size was determined equal to 391 subjects (199 working women and 192 housewives). The sampling method was simple random sampling. Data collection was done using library method and referring to the documents and as a field study. The research scope was locally the city of Karaj, Iran, and temporally the year 
2016. The data collection instruments were Goldberg and Williams (1998) General Health Questionnaire with 28 items and Cassidy and Long (1996) Problem Solving Questionnaire with 24 items that their validity has been confirmed by different researches because of being standardized tests. For data analysis, descriptive and inferential statistics were used in the environment of SPSS software.

\section{Research Findings}

\subsection{Descriptive Findings of Research}

The study of the education level of the sample showed that the highest frequency was related to Bachelor's Degree (31.7) and lowest frequency was related to Philosophy Degree (1). The study of the economic status of the sample showed that more than eighty percent of the sample group had average economic status (48.8) and optimal status (32.5). The study of the mental health variable in the two groups of working women and housewives showed that there was no significant difference between the mean scores of mental health components; however, the total score of the mental health in working women was higher than that of housewives (based on the scoring of the mental health questionnaire, the higher scores showed the lower mental health). Finally, the study of the problem-solving variable in working women and housewives showed that there was no significant difference between the mean scores of problem-solving components and the total score in working women and housewives.

\subsection{Inferential Findings of Research}

Hypothesis 1. Economic situation has a moderating effect on the relationship between problem solving and mental health.

So the question is that: Does economic situation moderate the relationship between problem solving and mental health?

To investigate this issue, the hierarchical multiple regression analysis was used that the results of which are presented in Tables 1 and 2 .

Before presenting the results of the analysis, it is noteworthy to mention that the assumption of independence of errors was evaluated by Durbin-Watson test which was obtained equal to 1.97. Since, the value for this test in the range of $0-4$ is satisfactory, we can say that this assumption is satisfied in the present study. To examine the multicollinearity assumption, the two indices of Tolerance and VIF were used. Tolerance value between 0 and 1 is ideal, and the more this number is the closer to 1 , the more it is ideal. According to the figures for the corresponding column in Table 2, it is clear that this index value is in the desirable range. On the other hand, the VIF index should not be higher than 10 and the corresponding column of numbers in Table 2 indicates that none of the numbers are higher than 10 . Therefore, the absence of multicollinearity assumption is satisfied.

Table 1. Summary of regression model to predict mental health by problem solving, economy and their interactive effects

\begin{tabular}{rccccccc}
\hline Rank & predictor & $\mathbf{R}$ & $\mathbf{R}^{\mathbf{2}}$ & Modified R2 & $\mathbf{F}$ & F Significance & Durbin-Watson \\
\hline $\mathbf{1}$ & Problem solving & 0.488 & 0.238 & 0.236 & 120.70 & 0.001 & \\
$\mathbf{2}$ & Economy & 0.488 & 0.238 & 0.234 & 60.20 & 0.001 & \multirow{2}{*}{1.97} \\
$\mathbf{3}$ & Problem solving*economy & 0.488 & 0.238 & 0.232 & 40.04 & 0.001 & \\
\hline
\end{tabular}

As can be seen in Table 1, at the first step the problem-solving was entered in the regression equation as a predictive variable. This variable alone explains $23.8 \%$ of variance of mental health; in the second step, the economy was entered in the regression equation. In this step, no value was added to the explanation coefficient. In the third step, the interaction of economy and problem solving was entered into regression equation. In this step, again no value was added to the explanation coefficient. 
Table 2. Regression coefficients to investigate the moderating effect of the economy on the relationship between problem solving and mental health

\begin{tabular}{cccccccc}
\hline Rank & predictor & B & Beta & t & Sig. & Tolerance & VIF \\
\hline $\mathbf{1}$ & Problem solving & -0.49 & -0.49 & -10.99 & 0.001 & 1 & 1 \\
\multirow{2}{*}{} & Problem solving & -0.49 & -0.49 & -10.76 & 0.001 & 0.96 & 1.04 \\
& Economy & 0.003 & 0.003 & 0.06 & 0.949 & 0.96 & 1.04 \\
\multirow{3}{*}{$\mathbf{3}$} & Problem solving & -0.49 & -0.49 & -10.74 & 0.001 & 0.96 & 1.04 \\
& Economy & 0.003 & 0.003 & 0.07 & 0.946 & 0.96 & 1.04 \\
& Problem solving * economy & -0.006 & -0.006 & -0.14 & 0.890 & 1 & 1.003 \\
\hline
\end{tabular}

B: Non-standardized regression coefficient; Beta: Standardized regression coefficient.

According to Table 2, beta coefficient is significant for the first step, i.e., problem solving independently has a significant contribution in predicting mental health. However, the beta for the economy in the second step is not significant; in other words, the economy independently does not have a significant proportion in predicting mental health. Beta coefficient in the third step, i.e., the interaction between problem solving and economy also is not significant; accordingly, we can say that the economy cannot act as a moderating variable in the relationship between problem solving and mental health.

Hypothesis 2: The economy has a moderating effect on the relationship between problem solving and mental health in working women.

So the question is that: Does economy moderate the relationship between problem solving and mental health in working women?

To investigate this issue, the hierarchical multiple regression analysis was used that the results of which are presented in Tables 3 and 4.

Before presenting the results of the analysis, it is noteworthy to mention that the assumption of independence of errors was evaluated by Durbin-Watson test which was obtained equal to 1.85. Since, the value for this test in the range of 0-4 is satisfactory, we can say that this assumption is satisfied in the present study. To examine the multicollinearity assumption, the two indices of Tolerance and VIF were used. Tolerance value between 0 and 1 is ideal, and the more this number is the closer to 1, the more it is ideal. According to the figures for the corresponding column in Table 4, it is obvious that this index value is in the desirable range. On the other hand, the VIF index should not be higher than 10 and the corresponding column of numbers in Table 4 indicates that none of the numbers are higher than 10 . Therefore, the absence of multicollinearity assumption is satisfied.

Table 3. Summary of regression model to predict mental health by problem solving, economy and their interactive effects

\begin{tabular}{cccccccc}
\hline Rank & predictor & $\mathbf{R}$ & $\mathbf{R}^{\mathbf{2}}$ & Modified R2 & $\mathbf{F}$ & F Significance & Durbin-Watson \\
\hline $\mathbf{1}$ & Problem solving & 0.478 & 0.228 & 0.236 & 57.67 & 0.001 & \\
$\mathbf{2}$ & Economy & 0.496 & 0.239 & 0.234 & 31.72 & 0.001 & 1.85 \\
$\mathbf{3}$ & Problem solving*economy & 0.496 & 0.235 & 0.232 & 21.04 & 0.001 & \\
\hline
\end{tabular}

As can be seen in Table 3, at the first step the problem-solving was entered in the regression equation as a predictive variable. This variable alone explains $22.8 \%$ of variance of mental health; in the second step, the economy was entered in the regression equation. In this step, 1.8 percent was added to the explanation coefficient. In the third step, the interaction of economy and problem solving was entered into regression equation. In this step, no value was added to the explanation coefficient. 
Table 4. Regression coefficients to investigate the moderating effect of the economy on the relationship between problem solving and mental health in working women

\begin{tabular}{cccccccc}
\hline Rank & predictor & B & Beta & t & Sig. & Tolerance & VIF \\
\hline $\mathbf{1}$ & Problem solving & -0.46 & -0.48 & -7.59 & 0.001 & 1 & 1 \\
$\mathbf{2}$ & Problem solving & -0.47 & -0.49 & -7.78 & 0.001 & 0.99 & 1.01 \\
& Economy & 0.13 & 0.13 & 2.16 & 0.032 & 0.99 & 1.01 \\
\multirow{3}{*}{$\mathbf{3}$} & Problem solving & -0.47 & -0.49 & -7.11 & 0.001 & 0.89 & 1.14 \\
& Economy & 0.13 & 0.13 & 2.03 & 0.043 & 0.93 & 1.07 \\
& Problem solving * economy & 0.005 & 0.001 & 0.001 & 0.999 & 0.83 & 1.21 \\
\hline
\end{tabular}

B: Non-standardized regression coefficient; Beta: Standardized regression coefficient.

According to Table 4, beta coefficient is significant for the first step, i.e., problem solving independently has a significant contribution in predicting mental health. The beta for the economy in the second step is also significant; in other words, the economy independently has a significant proportion in predicting mental health. Beta coefficient in the third step, i.e., the interaction between problem solving and economy is not significant; therefore, we can say that the economy cannot act as a moderating variable in the relationship between problem solving and mental health in working women.

Hypothesis 3: The economy has a moderating effect on the relationship between problem solving and mental health in housewives.

So the question is that: Does economy moderate the relationship between problem solving and mental health in housewives?

To investigate this issue, the hierarchical multiple regression analysis was used that the results of which are presented in Tables 5 and 6 .

Before presenting the results of the analysis, it is noteworthy to mention that the assumption of independence of errors was evaluated by Durbin-Watson test which was obtained equal to 1.99. Since, the value for this test in the range of 0-4 is satisfactory, we can say that this assumption is satisfied in the present study. To examine the multicollinearity assumption, the two indices of Tolerance and VIF were used. Tolerance value between 0 and 1 is ideal, and the more this number is the closer to 1 , the more it is ideal. According to the figures for the corresponding column in Table 6, it is obvious that this index value is in the desirable range. On the other hand, the VIF index should not be higher than 10 and the corresponding column of numbers in Table 6 indicates that none of the numbers are higher than 10 . Therefore, the absence of multicollinearity assumption is satisfied.

Table 5. Summary of regression model to predict mental health by problem solving, economy and their interactive effects

\begin{tabular}{cccccccc}
\hline Rank & predictor & $\mathbf{R}$ & $\mathbf{R}^{\mathbf{2}}$ & Modified R2 & $\mathbf{F}$ & F Significance & Durbin-Watson \\
\hline $\mathbf{1}$ & Problem solving & 0.473 & 0.224 & 0.220 & 54.56 & 0.001 & \\
$\mathbf{2}$ & Economy & 0.483 & 0.233 & 0.225 & 28.54 & 0.001 & 1.99 \\
$\mathbf{3}$ & Problem solving*economy & 0.487 & 0.237 & 0.225 & 19.39 & 0.001 & \\
\hline
\end{tabular}

As can be seen in Table 5, at the first step the problem-solving was entered in the regression equation as a predictive variable. This variable alone explains $22.4 \%$ of variance of mental health; in the second step, the economy was entered in the regression equation. In this step, 0.9 percent was added to the explanation coefficient. In the third step, the interaction of economy and problem solving was entered into regression equation. In this step, 0.4 percent was added to the explanation coefficient. 
Table 6. Regression coefficients to investigate the moderating effect of the economy on the relationship between problem solving and mental health in housewives

\begin{tabular}{ccccccccc}
\hline Rank & predictor & B & Beta & $\mathbf{t}$ & Sig. & Tolerance & VIF \\
\hline $\mathbf{1}$ & Problem solving & -0.49 & -0.47 & -7.39 & 0.001 & 1 & 1 \\
$\mathbf{2}$ & Problem solving & -0.47 & -0.45 & -6.83 & 0.001 & 0.94 & 1.06 \\
& Economy & -0.11 & -0.10 & -1.48 & 0.141 & 0.94 & 1.06 \\
\multirow{2}{*}{$\mathbf{3}$} & Problem solving & -0.49 & -0.47 & -6.81 & 0.001 & 0.85 & 1.17 \\
& Economy & -0.11 & -0.10 & -1.58 & 0.116 & 0.93 & 1.07 \\
& Problem solving * economy & -0.07 & -0.07 & -1.04 & 0.301 & 0.87 & 1.14 \\
\hline
\end{tabular}

B: Non-standardized regression coefficient; Beta: Standardized regression coefficient.

According to Table 6, beta coefficient is significant for the first step, i.e., problem solving independently has a significant contribution in predicting mental health. It is while, the beta for the economy in the second step is not significant; in other words, the economy independently does not have a significant proportion in predicting mental health. Beta coefficient in the third step, i.e., the interaction between problem solving and economy also is not significant; therefore, we can say that the economy cannot act as a moderating variable in the relationship between problem solving and mental health in housewives.

\section{Discussion and Conclusion}

The objective of the present study was to investigate the moderating effect of the economic situation on the relationship between problem solving skills and mental health in two groups of working women and housewives. To achieve this end, the population of women referring to Welfare Centers in the city of Karaj was used; and in this regard, to answer the questions the related data were collected and analyzed. As was seen, based on the descriptive findings, there is not a significant difference between the means of the mental health and problem solving variables in the two groups of working women and housewives. But the findings obtained from the study of the first question (Does economic situation moderate the relationship between problem solving and mental health?) showed that beta coefficient was significant for the first step, i.e., problem solving independently had a significant contribution in predicting mental health. However, the beta related to the economy in the second step was not significant; that is, the economy did not have an independent contribution in the predicting mental health. The beta coefficient in the third step, i.e., in the interaction of problem solving and economy also was not significant. Accordingly, we can say that economy cannot act as the variable moderating the relationship between problem solving and mental health. Also, the results obtained from analyzing the second question (Does economy moderate the relationship between problem solving and mental health in working women?), considering the beta coefficient in the first step, showed that problem solving independently had a significant contribution in predicting mental health. Also the beta coefficient related to economy in the second step was significant; in other words, economy also had a significant contribution in predicting mental health. Beta coefficient of the third step, that is, the interaction between problem solving and economy was not significant; consequently it can be said that the economy cannot act as a variable moderating the relationship between problem solving and mental health in working women. Based on the information resulted from the last analysis, that is, "the economy can moderate the relationship between problem solving and mental health", we can say that the beta coefficient was significant for the first step, that is, problem solving had independently a significant effect on predicting mental health; it is while, the beta coefficient related to economy was not significant in the second step; in other words, economy did not have an independent contribution in predicting mental health. Beta coefficient of the third step, i.e., the interaction between problem solving and economy was not significant. Accordingly, it can be said that economy cannot act as a variable moderating the relationship between problem solving and mental health in housewives.

As it was seen, according to statistical multiple analysis results and consistent with a research by Ahmadi Deh Qutbal-Dini (2010), the economy does not have an independent contribution in predicting mental health of the sample population. Despite the findings of the studies by Rezapour et al. (2010) and Nick Azin et al. (2013) that showed the importance and role of economy in moderating problem solving and mental health, what seems interesting in regression equation was insignificance of this variable. Perhaps one of the reasons that the result of this question was not consistent with earlier findings was the way of selecting the subjects, the type of subjects' responses, and the subjects' honest responses, etc. But the problem solving alone explains 23.8 percent of the variance in mental health. In other words, the problem solving ability is effective in increasing the level of mental 
health, but economy cannot act as a variable moderating the relationship between problem solving and mental health both in working women and housewives. It is suggested that the ways to strengthen mental health in housewives are studied except the economy status variable, as well as the factors effective in the field of mental health in working women are controlled and during meetings, working women are informed about the importance of mental health and the proposed ways to improve it are presented. In addition, the problem solving ability in people must be strengthened during the training workshops.

\section{References}

Agha Yousefi, A. R., \& Sharif, N. (2011). The relationship between students' problem solving styles and personal well-being. Journal of Thought and Behavior, 6(22), 79-88.

Agha Yousefi, A. R., Shaghaghi, F., Alipour, A., Karbasi, M., Panahi Shahri, M., Arkani, I., ... Polladi Ray-Shahri, K. (2011). General Psychology. Payam-e Noor University, Tehran.

Ahmadi Deh Qutbal-Dini, M. (2010). The relationship among family Socio-economic condition, learning strategies and mathematical problem solving ability in university students. Program developing, Research in Educational Sciences, 25, 110-130.

Angela, H., Nippert, A., \& Smith, M. (2008). Psychological stress related to injury and impact on sport performance. Physical Medicine and Rehabilitation Clinics of North America, 19(2), 399-418. https://doi.org/10.1016/j.pmr.2007.12.003

Bakhtiar, N. H., \& Pahlawan, S. A. (2012). The impact of education level and training Fordyce joy program on increasing liveliness (Masters thesis). University of Esfahan.

Bani Fatemeh, H., Shaham far, J., Alizadeh, E. M. B., \& Abdi, B. (2014). Measurement of Tabrizi Citizens' education level and the effect of education and gender on health knowledge, health-based lifestyle, and health-related life quality. Payesh Journal, 14(1), 85-92.

Barghandan, M., Enayati, M. S., \& Mehrabizadeh, H. M. (2009). Evaluation of the effectiveness of group training problem solving skills on mental health and marital satisfaction in spouses of male employees working in satellite plan. New Findings in Psychology, 95-107.

Barriuso-Lapresa, L., Hernando-Arizaleta, L., \& Rajmil, L. (2012). Children in Spain social inequalities in mental health and health-related quality of life in Spain. Pediatrics, 130(3), 528-535. https://doi.org/10.1542/peds.2011-3594

Bayani, A. A., Ranjbar, M., \& Bayani, A. (2012). Relationship between Social problem solving and Depression and social phobia in College Students. Mazandaran Journal of Medical Sciences, 22, 91-98.

Chinaveh, M. (2010). Training problem-solving to enhance quality of life: Implication towards diverse learners. Procedia-Social and Behavioral Sciences, 7(1), 302-310. https://doi.org/10.1016/j.sbspro.2010.10.042

Erozkan, A. (2013). The effect of communication skills and interpersonal problem solving skills on social self-efficacy. Educational Sciences: Theory \&Practice, 13(2), 739-745.

Esra, D. (2013). Adaptation of social problem solving for children questionnaire in 6 age groups and its relationships with preschool behavior problems. Edam Education Consultancy, 13(1), 491-498.

Gerkensmeyer, J., Johnson, C., Scott, E., Oruche, U., Lindsey, L., Austin, J., \& Perkins, S. (2013). Problem-solving intervention for caregivers of children with mental health problems. Archives of Psychiatric Nursing, 27(3), 112-120. https://doi.org/10.1016/j.apnu.2013.01.004

Hajjilu, J., \& Ramzi, S. (2014). The educational goals of Islam. In Social and Cultural Studies.

Hansson, K., \& Lundbland, A. (2006). Couple therapy: Effectiveness of treatment and long term follow up. Journal of Family Therapy, 28, 136-152. https://doi.org/10.1111/j.1467-6427.2006.00343.x

Jawaheri, F., Serajzadeh, S. H., \& Rahmani, R. (2010). The analysis of women's employment effects on quality of life (Case study: Women working in the Ministry of Agriculture). Women in Development and Politics (women Studies), 8(2), 143-162.

Kandemir, M. A., \& Gür, H. (2009). The use of creative problem solving scenarios in mathematics education: Views of some prospective teachers. Procedia-Social and Behavioral Science, 1(1), 1628-1635. https://doi.org/10.1016/j.sbspro.2009.01.286

Karami, J. (2012). The relationship between life skills and marital conflicts with mental health in couples. Journal of Counseling and Family Psychotherapy, 1(4), 461-472. 
Mohammadzadeh, J., \& Khosravi, A. (2012). The study of the relationship between purposes in life, coping styles with mental health among college students at University of Ilam. Journal of Studies in Health System, 8(6), 951-958.

Mousavi, S. R. (2014). The effects of maternal employment on their daughters' self-esteem.

Nick Azin, A., Shoairi, M. R., \& Naeeniyan, M. (2013). Health-related quality of life in adolescents: Health-treatment, socio-economic, gender and age differences. Developmental Psychology, Iranian Psychology, 9(35), 271-281.

Özdemir, Y., Kuzucu, Y., \& Koruklu, N. (2013). Social Problem Solving and Aggression: The role of depression. Australian Journal of Guidance and Counseling, 23(1), 72-81. https://doi.org/10.1017/jgc.2013.1

Phelan, J. C., Link, B., \& Tehranifar, P. (2010). Social conditions as fundamental causes of health inequalities: Theory, evidence, and policy implications. Journal of Health and Social Behavior, 51, 28-40. https://doi.org/10.1177/0022146510383498

Pugliese, C., \& White, S. W. (2013). Brief report: Problem solving therapy in college students.

Rezapour, Y., Fathi, A., Sardari, M., \& Shiralipour, A. (2010). The relationship between students' religiosity and socio-economic condition with life satisfaction through moderating the mental health components. Academic-Research Journal of Psychology, 5(19), 69-89.

Sadeghipour, Z. (2012). The study of socio-economic factors related to mental health in women working at Bandar Abbas hospitals (Master's thesis). Shiraz University, Faculty of Economics, Management and Social Sciences.

Shokohi, Y. M., Sharifi, A., \& Moatamed, Y. N. (2015). Effectiveness of training problem solving skills on parent-child interaction. Developmental Psychology, Iranian Psychology, 12(45), 3-14.

Steenbarger, B. (2007). Subjecting well being: Why it is important? Journal of soc psycho, 63(1), 364-385.

Toozandehjani, H. (2009). The analysis of created employment on the social, economic and cultural status of target population of Welfare Organization of Khorasan Razavi province. Journal of Educational Psychology, $1,6-17$.

Walker, O., Degnan, K., Fox, N., \& Henderson, H. (2013). Social problem solving in early childhood: Developmental change and the influence of shyness.

\section{Copyrights}

Copyright for this article is retained by the author(s), with first publication rights granted to the journal.

This is an open-access article distributed under the terms and conditions of the Creative Commons Attribution license (http://creativecommons.org/licenses/by/4.0/). 